\title{
Revista de la
}

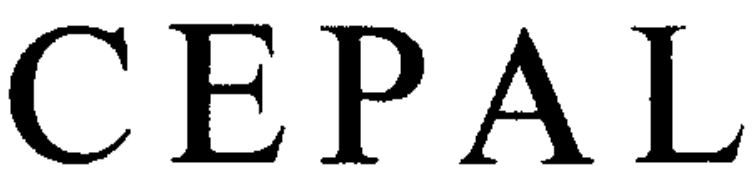

Director

\author{
RA U L PREBIS CH
}

Secretario Técnico

A DOLFO G URRIER I

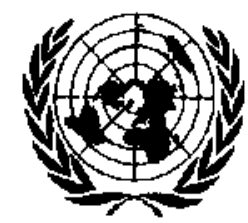

NACIONES UNIDAS

COMISION ECONOMICA PARA AMERICA LATINA

SANTIAGO DE CHILE / SEGUNDO SEMESTRE DE 1977 


\section{S U M A R I O}

La originalidad de la copia: la CEPAL y la idea de desarrollo

Fernando H. Cardoso

Para 'otro desarrollo': requisitos y proposiciones

Marshall Wolfe

Política fiscal y desarrollo integrado

Federico J. Herschel

Apuntes acerca del futuro de las democracias occidentales

José Medina Echavarría

Comentario de John Durston

Comentario de Carlo Geneletti

142

Comentario de Eduardo Palma

145

Comentario de Gregorio Weinberg

147

Comentario de Marshall Wolfe

150

Las pequeñas naciones y el estilo de desarrollo 'constrictivo'

Carlos Real de Azúa

El déficit de los servicios urbanos: ¿una limitación estructural?

Francisco Barreto y Roy T. Gilbert

Sobre el articulo de Raúl Prebisch, "Crítica al capitalismo periférico"

Comentario de Joseph Hodara

Comentario de Eugenio Kossarev

Comentario de Octavio Rodriguez

Comentario de Marshall Wolfe 
REVISTA DE LA CEPAL

Segundo Semestre de 1977

Apuntes acerca

del futuro de

las democracias

occidentales

\section{José Medina Echavarría*}

¿Cuál será el futuro de la democracia en América Latina? Medina Echavarría insinía una respuesta a esta interrogante basada en el análisis de la controversia que se ha desarrollado durante los últimos años en los paises europeos sobre las perspectivas de sus democracias. Por supuesto, no cree que en América Latina se reproduzcan mecánicamente los procesos políticos de aquéllos sino que la semejanza de algunas condiciones y problemas y el contacto mutuo hacen plausible que se asemejen también algunas soluciones.

Después de una rápida consideración inicial sobre el autoritarismo y la tecnocracia, se refiere a la ampliación de la intervención estatal, a trayés del análisis de hipótesis de Heilbroner y Bell. A partir de alli penetra en la cuestión central de la crisis de la democracia, tal como es interpretada por las concepciones conservadoras, liberales y marxistas, y finaliza con una aplicación de esas hipótesis a América Latina. En esta última parte, alude en especial a las telaciones entre democracia y desarrollo económico, a la sobrecarga de demandas y a la legitimidad de los principios democráticos, y concluye con una hipótesis razonablemente optimista sobre el futuro de la democracia en nuestros paises.

A continuación del artículo se incluyen comentarios que algunos colegas de la CEPAL y del ILPES le hicieron al autor en un seminario intemo.

* Consultar de la División de Desarrollo Social de la CEPAL.

\section{I. \\ Inquietudes en América Latina}

\section{Situaciones de hecho y su interpretacion}

Por lo pronto sólo importa consignar una situación de hecho. De acuerdo con los observadores de la realidad política latinoamericana - cualquiera que sea su motivación- parecería casi imperar en ella - por el número y la importancia de los países considerados- una forma de gobierno calificada de autoritaria. Cierto es que el adjetivo no advierte bien sobre los diversos matices de sus manifestaciones. Cabe, en efecto, un ejercicio enérgi co del poder que escapa, sin embargo, a ese calificativo cuando su autoridad se ofrezca dentro de las competencias constitucionales de un régimen representativo. La calificación de autoritarismo se refiere por tanto a que en el ejercicio de esa más fuerte autoridad se prescinda en mayor o menor medida de la participación de la ciudadanfa en la toma de decisiones de los poderes públicos.

Consignado el hecho no puede faltar su interpretación. Sea en su intención estrictamente funcional y científica $o$ que orientada por posiciones de valor se pretenda como justificación o como rechazo. Hasta qué punto sea estrictamente posible la primera postura es desde luego cosa problemática que no cabe rozar por el momento.

Lo que interesa es tomar nota simplemente de que las interpretaciones $\mathrm{co}$ rrientes son de dos tipos, aunque no siempre de carácter excluyente. Una explica la existencia del fenómeno autoritario por las deficiencias en un momento dado del sistema institucional, bien de la constitución politica misma o de sus mecanismos de ejercicio, los partidos 
políticos en particular. Sin embargo, esos factores negativos de la estructura política se ofrecen para algunos en su punto crítico, cuando el Estado determinado por ella tuvo que enfrentarse con las tareas de la modernización económica. Es decir, los defectos institucionales se hicieron patentes en el momento de intentar la denominada industrialización sustitutiva o de avanzar más allá de ella. Por consiguiente, esa estricta interpretación política en su punto de partida y sin renunciar a su signo viene a coincidir, o confundirse, con la interpretación pura o especialmente económica, cuyo interés se centra en los sistemas de producción y distribución; o dicho con mayor precisión, en el fenómeno del desarrollo económico. Y la tesis general a este respecto es que los países en retardo económico no pueden seguir para supetarlo las vias tradicionales de los países democráticos, y que no les cabe por eso eludir un momento autoritario sea por un proceso de movilización puesto en marcha por un grupo doctrinal o una figura carismática, sea por un incremento de la capacidad de decisión en el sector ejecutivo del Estado heredado. La segunda alternativa se destaca como la más plausible cuando se sostiene que la interferencia de los elementos representativos que ese Estado mantenía fue incapaz de resolver los conflictos de intereses que todo desarrollo económico provoca, dejando a la deriva de continuo la imprescindible toma de decisiones en la orientación de una política definida.

Claro es, como la situación de los distintos países es diversa en cuanto al carácter de su Estado autoritario, una y otra interpretación para ser válidas tienen que completarse con el análisis pormenorizado de los procesos históricosociales que en cada uno de ellos se dieron.
Pero a veces la explicación sociológica puede intentar simplificar esa yariedad, tipificando sus condiciones estructurales; tal como se ha hecho desde la perspectiva de' la teoría de la dependencia. Sin embargo, estos u otros detalles en el contenido de la interpretación no anulan la escueta contraposición en sus líneas generales de las explicaciones ofrecidas. Ahora interesa no pasar de aquí.

\section{Cuestiones indecisas}

Dos cuestiones en las interpretaciones consideradas quedan en condición ambigua o problemática, de lo que conviene al menos tomar nota. Una es la calificación de tecnocrático que se añade por lo general a la del carácter autoritario del gobierno. Su problematicidad consiste en que el predominio del proceder tecnocrático suele estar unido en los teóricos del capitalismo avanzado a un grado extremo de concentración económica, no siendo por tanto de esperar allí donde esa concentración es mucho menor. En caso contrario sería necesario aclarar de otra manera la presencia de tendencias tecnocráticas. Asimismo, la afirmación del carácter autoritario de un gobierno nada dice en principio sobre la amplitud de su intervención tanto en el campo económico como en el social; es más, pueden señalarse Estados autoritarios que subrayan la naturaleza estrictamente subsidiaria de su actividad. ¿Es esto último efectivo e incluso realmente posible? En términos generales habría que preguntarse a este respecto si toda posición autoritaria exige la mayor amplitud del intervencionismo o, al contrario, si toda ampliación de este intervencionismo requiere la forma autoritaria antes descrita. Cuestión importante para lo que pronto saltará a la vista en lo que sigue. 


\section{Situación a mediano plazo en los países occidentales}

La situación de hecho de una región donde prevalecen según lo dicho formas autoritarias puede ser el punto de partida de una serie muy diversa de planteamientos. En este momento, cuando se persigue una orientación prospectiva, no se pretende considerar por sí mismas las alternativas posibles en la duración de esas formas autoritarias, sino de escrutar las posibilidades de su continuidad y mudanza en función de la vitalidad de las formas políticas democráticas tradicionales en los paises con mayores contactos y conexiones culturales con los latinoamericanos fuera de la región. En una palabra, ¿qué es lo que se presume como posible respecto de las grandes democracias industriales en un futuro próximo?

En este tipo de prospección conviene aclarar de antemano dos aspectos fundamentales. En primer lugar, no se postula un tipo de determinismo cuyo solo enunciado lo mostraría incorrecto. Es decir, no se cree a priori en modo alguno que to que suceda en uno $u$ otro sentido en la experiencia de las grandes democracias capitalistas tenga que reproducirse de modo completo, y sin alteraciones, en los regímenes políticos de los países latinoamericanos, o que éstos no puedan hacer cosa distinta que reaccionar siempre de manera imitativa o de reflejo inmediato. Se postula simplemente una mayor interdependencia y contacto $\mathrm{mu}-$ tuo en una serie de países, que sometidos a procesos semejantes extiendan a su conjunto condiciones también similares con la estabilización lograda en la solución de sus problemas. No se trata pues de nada forzado ni puramente mecánico. El segundo aspecto fundamental consiste en aclarar el porqué de ciertas inclinaciones de la investigación futurológica. En ésta se persigue adelantar tendencias y proyecciones de todo tipo y sabido es cuanto pesan las de estricto carácter tecnológico, pero sin duda su más fuerte aguijón existencial se pone en el futuro de la condición humana $y$, dentro de ella, por tanto, en el destino de plenitud o malogro de los que todavia se consideran valores fundamentales de la civilización. El horizonte de esa condición pudiera ser la del imperio de un absoluto cesarismo autoritario, pero no está en principio negado que sea incapaz de conservar en distinta medida los elementos liberales y democráticos a que todavía se aspira, cualquiera que sea el cuadro de los soportes tecnológicos y de las estructuras económicas en buena parte condicionadas por ellos. Y si bien no hay modo de prescindir en toda prospección de las tendencias efectivas de los factores materiales - como se verá en seguida- no es menos cierto que semejante tarea carece de auténtico sentido si no persigue como su última meta anticipar lo que pueda ocurrir a la vida humana con sus aspiraciones y sufrimientos. ¿Podrá subsistir la democracia liberal dentro de condiciones económicas y técnicas muy distintas de lo que fueron hasta ahora? La pregunta mantiene su validez teórica como problema, inmune a las posiciones emocionales de pesimistas $u$ optimistas.

A nadie podrá aparecer como injustifícado que exista una declarada preocupación por el funcionamiento eficaz de la democracia en algunos países que hasta ahora se ofrecían como modelos históricos y doctrinales de la misma. Esa 
preocupación indica por sí misma que proviene de personas con manifiesto interés por conservarla; es decir, de intelectuales y políticos que se descubren en este sentido como conservadores, porque las fallas y amenazas que destacan, los límites y peligros que denuncian no derivan cabalmente de una posición doctrinal negativa. En este escrito se prefiere metódicamente buscar la apoyatura inicial de estudios de inspiración conservadora, $\sin$ que sea lícito en el momento oportuno hacer caso omiso de la crítica de la izquierda, tanto de la tradicional como de la denominada 'nueva', más estimulante a veces en sus desplantes que la primera. ¿Cómo se ve la 'gobernabilidad' de las grandes democracias capitalistas a mediano plazo? Un giro expresivo que está lejos de ser evidente por sí $\mathrm{y}$ poco afortunado por consiguiente. Pues no se trata de saber si las democracias son poco o apenas gobernables - ¿por quién en este caso? - sino más bien de si los palses que desde hace tiempo viven en régimen democrático son capaces de un gobierno más eficaz del que ahora presentan. Lo que se demanda, sin declararlo, es si cabe o no esperar en tales paises una mayor dosis de gobierno; lo que implica, dicho en forma inversa, que en ellos se gobierna poco o no lo suficiente. ¿Cuáles son las razones de esa anemia de autoridad y de que se exija por lo tanto su mayor vigorización? Este ha sido el planteamiento de un estudio conjunto de una 'Comisión Trilateral', justificada en su denominación porque pretende explorar el problema en sus tres lados evidentemente más decisivos: Estados Unidos, Europa y Japón. Su adopción como base o punto de partida en este instante del presente escrito parece recomendable no sólo por aquellas dimensiones $y$ por razón del prestigio personal de sus autores, sino, como antes se dijo, por la posición conservadora más que revolucionaria de los mismos. En ese trabajo, como en otros semejantes, el destino de la viabilidad democrática aparece reiteradamente vinculado al desarrollo económico. Por eso conviene, antes de entrar en su examen un poco más detallado, destacar un supuesto común que subyace decididamente también como hipótesis en estas páginas. La hipótesis de que no parece presumible a mediano plazo una conmo ción del capitalismo que pueda semejarse incluso a la traumatica del affo treinta. En su forma positiva la hipótesis apoya la seguridad de que por lo menos en los próximos veinticinco años el sistema será todavía capaz de un crecimiento sostenido, tal como se mantiene en el reciente informe de W. Leontief.

Supuesta semejante hipótesis, en una u otra de sus formulaciones, las dos previsiones más generales que de modo razonable deben tenerse en cuenta son las siguientes. Por un lado, se anticipa que en los próximos affos se dará en todos los países occidentales una ampliación sostenida en el campo económico de la intervención estatal. $Y$ que en el campo político, por esas y otras razones, los regimenes democráticos tradicionales enfrentarán pruebas considerables, aunque de naturaleza no distinta de las que han conocido en estos últimos tiempos. Se trata ahora de pasar en forma muy esquemática y concentrada a la consideración de los puntos principales.

\section{Ampliación de la intervención estatal}

Dejando de lado toda posición revolucionaria, desde perspectivas relativamente conservadoras, la tesis de la ampliación creciente del intervencionismo estatal en la vida económica se ofrece hoy princi- 
palmente a través de dos formas de análisis, si no incompatibles si por lo menos de argumentación diferente.

\section{a) Exigencias de una mayor planeación}

La primera, representada por R. L. Heilbroner, afirma que la continuidad en los años inmediatos de la 'business civillzation', habrá de exigir un predominio creciente de ta planeación. Pues parece previsible que todas las economias capi talistas tengan que enfrentar a plazo medio: 1) la regulación de los desórdenes generalizados que tienden a producir; 2) la regulación asimismo de otros desórdenes o trastornos de tipo localizado; y 3) la reacción contra las amenazas que se están manifestando en el medio natural. De qué manera estas ineludibles exigencias de planeación $\rightarrow$ con el más fuerte peso consiguiente del Estado en la vida económica- habrán de repercutir en el sistema democrático de gobierno es cosa que Heilbroner no examina. Lo único que nos interesa ahora es su tesis escueta, frente a otros políticos e intelectuales más conservadores, de que al capitalismo actual no le queda para seguir en vida otra alternativa que una mayor planeación. A través de qué mecanismos políticos pueda llevarse a cabo no parece tema de su preocupación inmediata; lo que permite quizá suponer que esa amplitud de la intervención estatal pueda llevarse a cabo dentro de las instituciones democráticas. Cosa que por el momento nos basta para nuestras consideraciones, las cuales tampoco tienen que recoger en consecuencia lo que el autor piensa sobre el futuro más lejano del sistema, como no sea anotar el dato de que incluso puesto frente a su total mudanza reafirma, no sin cierta melancolía, el valor de la autonomía de la persona como el valor supremo de la tradición occidental.

\section{b) El Estado como Hacienda}

A esa misma presunción futurológica de una mayor amplitud de la intervención estatal en los tiempos venideros llega también otro economista, notoriamente conservador o de derecha, por vía de un análisis muy original y sugestivo. Nos referimos a D. Bell, también enfrentado con la supuesta crisis del capitalismo. No es ninguna novedad, pues ya hace años que se viene repitiendo de diversas maneras la idea de que debe limitarse la autonomía del sistema económico - como si fuera el ánico sistema social existente-, subordinándolo a valores extraeconómicos considerados como superiores por la conciencia moral del hombre. Ni tarapoco es original en la descripción emṕrica la afirmación de que tal sistema, capaz de regular con alguna eficacia los intereses públicos o privados sujetos a los mecanismos del mercado, se muestra sumamente deficiente en el mantenimiento de los servicios públicos, que si bien benefician a otros legitimos intereses humanos, éstos no se pueden medir exactamente sin embargo por aquellos mecanismos. El atractivo intelectual de las reflexiones de Bell sobre estas cuestiones consiste en la innegable plasticidad de su enfoque. Ya en una obra anterior a la que ahora más nos atañe, al estudiar el funcionamiento contemporáneo de las 'corporaciones', había mostrado a través de las mismas la tensión de lo que denominaba 'Economizing \& Sociologizing modes', una tensión fácilmente generalizable a la totalidad del sistema. Lo que significaba que la preocupación puramente económica por la rentabilidad tenía su compensación y su freno en la preocupación sociológica por los efectos en las relaciones humanas que se producian. De hecho esa tensión apunta históricamente 
a que el avance de semejante sociologización supone en su precipitado inevitable, no siempre conscientemente buscado, la inserción del sistema económico en un sistema social más amplio, orientado por finalidades distintas de las de aquél (un camino que quizá hubiera podido seguir E. Heimann para demostrar sus postulados fundamentales).

Pero para el punto en que estamos, el de la ampliación cada vez mayor del Estado en la vida económica, tiene mayor interés un capítulo del discutible y discutido libro del mismo Bell, en que apoyándose en un viejo y casi desconocido artículo de J. Schumpeter, muestra la inexorabilidad de esa expansión -aparte de otros temas no menos fundamentales-, develando la realidad del Estado contemporáneo como 'sistema fiscal', como la articulación de la Hacienda Pública de un país. No es cosa de entrar en los detalles del argumento ni en la calificación de su originalidad y validez. La hacienda familiar habla sido el único objeto económico del mundo clá sico (Aristóteles) y M. Weber había dedicado un largo capitulo al sistema de hacienda como el correspondiente a la economía de Oikos - predominantemente natural- que prevalece en extensos ámbitos históricos, antes, claro es, del imperio de una u otra forma de capitalismo. La Hacienda Pública, como siguió hasta hace poco denominándose en Europa el sistema fiscal, nace con el Estado moderno y a su servicio. Pero aún su continua expansión no transgredra los límites que ese mismo Estado se había impuesto frente al sistema económico liberal, un sistema que si atendía a las necesidades o deseos individuales, era a través de su satisfacción autónoma en el juego del mercado. Pero la complicación de la vida contemporánea no solo obligó al Estado a cuidar de la viabilidad de ese mercado - manteniendo la exigencia de la acumulación-, sino a hacer frente a las diversas demandas de individuos o grupos alimentados por estímulos culturales y que no podian satisfacerse en principio por el mercado. En este sentido el Estado como la Hacienda Pública de un país aumenta considerablemente de volumen, poniéndose en peligro de quiebra si no equilibra adecuadamente sus gastos fiscales. El problema del Estado actual es que no puede desentenderse de la doble función que históricamente se le ha impuesto: continuar con la coordinación del sistema económico -manteniendo la acumulación que necesita- $y$ satisfacer de una u otra forma el cúmulo incesante de las nuevas necesidades y deseos de los individuos y grupos sociales de su propio ámbito. Lo singular de estas nuevas demandas es que se muestran cada vez más como pretensiones 'casi' legales - si se quiere, con el carácter de derechos públicos subjetivos-, que sólo pueden colmarse en su multiplicidad y antagonismos por decisiones estrictamente políticas. No extrañará que este punto aparezca, como veremos, en todos los análisis de la democracia actual.

Lo que todo esto pueda valer como sintoma de una contradicción del sistema económico y por su repercusión en los dilemas del desarrollo, así como la solución política que nuestro autor propone -una restauración del liberalismo-, no es cuestión que ahora nos incumba. Buscábamos nada más, ateniéndonos a las opiniones de otro economista, encontrar de nuevo las anticipaciones prospectivas del anterior: el hecho de la previsible ampliación del intervencionismo estatal en el próximo futuro de las grandes democracias industriales. Pero no puede dejarse de consignar -porque el tema es obsesivo en el pensamiento de la nueva izquierda y dado que antes se 
mencionó la supuesta tensión entre los enfoques económicos y sociológicosque para Bell uno de los más decisivos dilemas del nuevo Estado como Public Household es el que plantea la relación entre eficiencia y equidad, en qué forma será posible el aumento de la capacidad productiva de una sociedad al tiempo que se restringen o limitan ciertos tipos de consumo. El principio de equidad pertenece también a la vertiente liberal, rozada asimismo por Heilbroner desde el ángulo de su soporte personal. Vengamos ahora al otro elemento de la anticipación prospectiva que aparece conjuntamente con el de la expansión de la actividad estatal y que pudieran considerarse en principio independientes, aunque de hecho no sea asi.

\section{Resquebrajamientos de la democracia}

Se presume para el inmediato futuro una crisis de la democracia en los grandes palses que mantienen por el momento ese régimen polftico; debiendo entenderse semejante crisis - título del informe antes mencionado- en un sentido etimológico estricto, el de cierto momento en la evolución de un sistema que ofrece suficientes manifestaciones de vacilación y trastorno, como para indicar un estado de transición, que no excluye tanto su recuperación y fortalecimiento como su definitiva descompostura $y$ ruina. Por otra parte, esa crisis que se proyecta hacia el futuro no hace sino arrastrar dificultades ya observables en el inmediato pasado, y por tanto en la actualidad.

\section{a) Interpretación conservadora}

Para enfrentar su examen y las predicciones existentes conviene recurrir a una clasificación, defectuosa como toda otra posible, pero capaz de imponer cierto orden expositivo. Los preocupados por el resquebrajamiento de la democracia presente y futura se agrupan en torno de actitudes y motivaciones conservadoras, predominantemente liberales o de un negativismo radical. E] informe de la 'Comisión Trilateral' se incluye singularmente en el primer grupo, dentro de una teoría técnicamente funcional. En esta posición se destacan como factores o causas de las crisis democráticas, estos cuatro principales que conviene reseñar de antemano; i) desajustes de tipo institucional; ii) 'sobrecarga' de las demandas frente al Estado, inducidas por la teoria y el desarrollo efectivo de la tradición democrática; iii) conexiones supuestamente funcionales con el desarrollo económico; y por último, iv) la estrechez creciente de sus ámbitos territoriales frente a las interdependencias globales en el mundo contemporáneo, sobre todo en su sector económico. Es posible mostrar la presencia de esos factores en todos y cada uno de los países considerados, aunque sea obligado decir de inmediato que subsisten grandes diferencias de país a pais por razones estructurales o de tradiciones políticas. Lo que conviene retener para evitar su repetición, donde no sea especialmente oportuno.

\section{i) Desajustes institucionales}

La tesis sobre los desajustes de tipo institucional es la menos novedosa porque ya se viene insistiendo desde hace tiempo en una $u$ otra de sus manifesta ciones. Se refiere a las relaciones entre los poderes legislativo y ejecutivo, al furcionamiento ineficiente de los partidos políticos, y a las inseguridades del comportamiento electoral del ciudadano medio frente a los mismos. Desde hace años se ha insistido en la debilidad técnica del Parlamento, en cualquiera de sus 
formas, frente al Ejecutivo y su Adminis tración, cuyo mayor saber y preparación tecnico-científica impone con escasas dificultades sus decisiones fundamentales en la forma de proposiciones y proyectos de ley. Frente a esa situación de hecho se han presentado diversas soluciones, que desde la instauración de comisiones técnicas al servicio de los legisladores, llegan a los proyectos de continuo renovados acerca de una representación de intereses profesionales, sea paralela o articulada al Parlamento polftico. Sobre los partidos se ha reiterado su falta de representatividad, su existencia hermética frente a los antagonismos de las demandas sociales, dejando así de llenar la función que la terminologia moderna denomina 'articulación de intereses' (la falta de relación y proporción entre los 'insumos' políticos de la población y los productos o resultados de las decisiones legislativas). En las formas más extremas de la crítica de la nueva izquierda, los partidos y el Parlamento sólo son un instrumento deferente, que cumplen sin embargo un papel importante, el constituir de hecho los núcleos necesarios para la legitimación del sistema La observación de tipo conservador se limita a sefialar con métodos descriptivos la disminuida atracción que los partidos ejercen sobre el electorado, sobre todo cuando en sus coaliciones tácticas se distancian tan sólo por motivos electorales acerca de cuestiones tri viales y del momento (denotadas por la investigación demoscópica), y no en cambio por la aceptación de posturas decisivas, en enfrentamiento sobre las grandes cuestiones nacionales. De pais a país varía la situación, insistimos, así como en el caso del mayor o menor dominio de la Administración sobre el Parlamento (tipos extremos, Italia y Francia), cuando esto no se complica con las divisiones internas de las mismas
Cámaras frente a la Presidencia, como en los años recientes de la experiencia nor. teamericana, la Presidencia 'imperial' de otrora frente a la maniatada posterior. La falta de credibilidad o entusiasmo por las figuras de los dirigentes políticos y la apatía o los movimientos zigzagueantes del electorado se atribuyen en primer lugar a estas circunstancias, que se observan quizá como transitorias en algunas partes o como derivadas de lo que parece funcionalmente ser el resultado de una 'sociedad bloqueada'. Se entiende, por los grandes cuerpos. ad ministrativos.

ii) Sobrecarga de las demandas

Un buen número de observadores del funcionamiento defectuoso de la demo cracia actual coinciden, con expresiones diferentes, en señalar como uno de los principales factores de su crisis lo que algunos denominan la sobrecarga de las demandas que tolera. Demandas, se entiende, de aportaciones y ayudas por parte del Estado. En este sentido, semejante imputación no sólo no es clara sino más bien equívoca. La mayor cantidad de exigencias $o$ peticiones frente a la actividad del Estado no es en modo alguno patrimonio del gobierno democrático, pues to mismo ocurre en cualquiera otra de sus formas en la medida en que tales demandas son el resultado de la complejidad intensificada de la vida social - de sus supuestos tecnológicos-, $y$ de la menor transparencia cada vez asimismo más acentuada que ofrece en su conjunto. Los Estados autoritarios no se encuentran de ningún modo exentos de las presiones de esa sobrecarga.

En los países de tradición liberaldemocrática parecería perfectamente explicable y natural la presencia de la mencionada sobrecarga, cuando ésta no es otra cosa que el desarrollo histórico de los principios mismos que sustentan a esos regímenes. Las aspiraciones que ne- 
cesariamente fomentan han ido dilatándose en la proporción en que la conciencia ciudadana fue percibiendo como cada vez más realizable buena parte de sus pretensiones. E1 mejor cuidado de la salud, por ejemplo, se alimenta con los progresos mismos de la medicina, haciéndose patente la injusticia que supone su limitación a algunos sectores. Sin embargo, la imputación de esa demanda excesiva apenas encubre en esos países la percepción de una inconsistencia profunda en los valores que sostenían su civilización centenaria, la del proclamado ind ividualismo radical. $\mathrm{El}$ individuo como centro responsable de toda actividad -no sólo la económica-, quien sólo necesitaba para su ejercicio de las garantías otorgadas por un Estado neutral y distante. No es del caso reseñar la larga historia de los distintos episodios que han hecho cada vez menos alcanzable la realización plena de ese ideal, aunque se siga pensando con justeza que no cabe imaginar civilización alguna que intente de verdad volverse de espaldas a las fuerzas individuales únicas auténticamente creadoras. Pero conviene evitar ahora cualquiera digresión de carácter cultural, por apretada que sea.

En el análisis empirico de las dificultades del gobierno democrático, frente al exceso de las peticiones que se le hacen, conviene insistir en dos aspectos ya reseñados o conocidos. Pues en efecto dada la enorme distancia entre el individuo concreto y el Estado abstracto, las demandas del primero frente al último necesitan de la interposición de mecanismos reguladores e intermediarios capaces de juzgarlas en cada caso según su peso e importancia. Pero sin ir más allá, hasta la valorización, por ejemplo, de la vieja idea durkheimiana sobre la necesidad de 'corpes intermédiaires', se trata ahora de remediar las fallas de los instrumentos de ajuste ya existentes, los partidos políticos en particular - para no mencionar otras asociaciones profesionales- en el cumplimiento de su principal tarea, la necesaria 'articulación' y compensación de la multiplicidad de los intereses presentes en un momento dado de la vida social, de modo de hacerlos oportunamente viables. Es posible que la supuesta 'sobrecarga' se produzca las más de las veces por la forma de aluvión en que se presentan los intereses, haciendo imposible su cumplimiento de esa manera. En este sentido el evidente problema de la demanda excesiva es de carácter institucional y por tanto superable con las reformas adecuadas de tal carácter.

El otro aspecto de esa amenazante sobrecarga es quizá más grave. El hecho de que las demandas actuales (los deseos y necesidades) de muchos grupos e individuos se presenten en forma perentoria como pretensiones casi legales, que traspasando los límites de la proclamada igualdad de oportunidades en el punto de partida exigen en realidad igualdades efectivas por su contenido; dan motivo de esta suerte a esa revolución de 'facultades' de cuasi derecho público (the rising revolution of entitlements) de que ha hablado uno de los autores antes mencionados. Las exigencias de un reconocimiento distribuido por cuotas ha sido el caso típico en los Estados Unidos y no sólo en ese pars. Y consiste en un caso más grave que el anterior porque la posible solución no está en la revitalización de instituciones conocidas, sino en una renovada determinación constitucional de los alcances del viejo liberalismo. Por eso el tema preocupa a las tendencias actuales del pensamiento 'restaurador', esforzado por conocer y precisar lo que todavía permanece válido del pasado. Pues en caso de renuencia a acceder a los impulsos de esa forma de pensamiento, 
habria que aceptar sin más las interpretaciones de algunos neomarxistas que en complicada teorfa 'funcionalista' declaran como típico de las formas democtáticas del capitalismo avanzado (tardfo en su terminología), la prosecución de una politica 'preventiva' de la crisis, que determina de facto de manera tecnocrática la prioridad entre tales demandas sociales, dejando sin atención y a su propia suerte aquellas que no ponen en peligro la viabilidad del sistema (Claus Offe). Posición que de hasta cierto punto se muestra de acuerdo con la tesis conservadora sobre el sobreexceso de demandas ante el Estado actual, sin darle sin embargo posibilidades de una salida realmente democrática. Los pensadores liberales que parten de la inexorabilidad - de la conveniencia incluso del conflicto-, de la pugna entre los diversos requerimientos estimulados por el propio medio social, tienen naturalmente que prestar a este punto, como se verá, una atención especial.

De hecho el problema de la superabundancia de pretensiones a que tiene que hacer frente el Estado democrático, representa una situación sociológicamente ineludible, sin que su solución pueda consistir en el silenciamiento o recorte arbitrario de unas u otras de entre ellas. Una solución que tampoco por cierto puede intentar el Estado autoritario sin incurrir en sus correspondientes peligros.

El tema de la sobrecarga de peticiones de las distintas unidades sociales -individuos o grupos- toma a veces en la discusión teórica aspectos o rumbos paradojales. Pues puede interpretarse en este sentido la crisis de la democracia como un 'exceso' de democracia. Y' frente al postulado clásico de que los males de ella sólo se curan con más democracia, algunos análisis funcionalistas actua les solo ven esa cura, por el contrario, en un recorte de la misma. No dicho así, claro es, de tan bronca e impetuosa manera, sino mostrando la existencia de elementos disfuncionales en la organización democrática, que permiten afirmar de qué manera y en qué grado requiere semejante sistema político muchas veces para su eficaz mantenimiento cierta medida de apatía y de desinterés políticos: ¿Hay una distancia exactamente determinable entre una democracia limitada en función de su eficacia y un gobierno autoritario? Pues no se trata ahora de la mayor o menor cantidad de demandas que pueden paralizar la toma de decisiones de un gobierno, sino del todo esencial de la democracia como participación política.

No sería en modo alguno fácil la formulación y consejo de remedios apropiados si resultara ser cierto el proceso cíclico que se ha pretendido observar en algún pals determinado. Un proceso mediante el cual todo incremento en la 'participación' llevaría al cabo a una polarización de la sociedad, la cual a su vez induciría a la apatía y al desinterés políticos, creando así situaciones en que acabaría por imponerse una percatación generalizada de la ineficiencia de la acción politica. Sorpresas del funcionalismo.

Pues si no se quiere que el argumento conduzca directamente a una postura autoritaria no deja otro escape, a su pesar quizá, que el correctivo de una línea de defensa permanente de naturaleza tecnocrática, capaz de romper con la temerosa repetición del mencionado proceso cíclico. Pero la dominación tecnocrática, a la que conducen otras tendencias de la estructura social, es cabalmente la que se niega como admisible desde el postulado tradicional de la intervención política mayoritaria y popular. 


\section{iii) Democracia y desarrollo}

En la década de los sesenta, sociológos de unos y otros países occidentales se enfrentaron acuciosos ante un fenómeno social que algunos se atrevían a calificar como nuevo o antes no sucedido, aunque variara la terminologia con que lo trataban de apresar. Señalaban en todos los paises industriales occidentales el paulatino avance de una tendencia igualitaria que sin ser en modo alguno completa -status, ingreso y cultura-, estaba ya produciendo una aproximación entre las diferentes clases y estratos sociales, hasta el punto de promover en muchos aspectos cierta homogeneización. Subsistían notorias desigualdades en el campo de los ingresos, pero su incremento relativo en los sectores antes más negativamente afectados parecía atenuar las más arraigadas tensiones consuetudinarias. Una especie de ancha capa intermedia -cualquiera que fuera su nombre- habia mejorado sus condiciones de vida material, permitiendo a sus miembros poder aceptar como tolerables diferencias todavía muy marcadas en la cúpula de la pirámide de población. Estos sociólogos, no sólo por la réplica doctrinal de sus opositores, no se engañaban en modo alguno, sobre la existencia de tales limitaciones en su interpretación, lo que les impedía negar de plano la realidad del antagonismo históricamente heredado. Sin embargo, insistían como en algo promisorio en que el conflicto o los conflictos, dada su menor magnitud, habían podido ser institucionalizados, y que la aceptación por los grupos, antes en tensa pugna, de semejante institucionalización no sólo aminoraba agudezas sino que permitía soluciones temporales cada vez más duraderas.

Pero aparte y al lado de esa atenuación del conflicto -en las cuestiones de trabajo sobre todo- la relativa amplia- ción asimismo de la educación y los efectos de los medios masivos de comunicación - prensa, radio y televisión-, habian logrado una homogeneización cultural antes inexistente. En Europa, a pesar de la persistencia de los partidos marxistas y de las fuerzas sindicales, los obreros parecían haber renunciado a su propia cultura diferenciada y adoptaban cada vez más los modos generalizados de la vida 'burguesa'; sobra además mencionar en este caso a los Estados Unidos donde apenas nunca se dieron tales fenómenos. Nada extrañará que teniendo en mente lo ocurrido en las tres décadas posteriores a la guerra, algunos celebren esos años tanto como los del triunfo renovado del capitalismo como los de la fuerte vitalidad de los regímenes democráticos en que se daba. Y que por tanto, a la inversa, muchos comenzarán a inquietarse por la continuidad de la vida democrática ante las dificultades que en ella comenzaron a observarse desde los primeros tropezones de la expansión económica. La tesis que estos autores plantean en consecuencia, es la del paralelismo entre desarrollo económico y democracia. En los momentos del pasado auge la participación en términos absolutos en un mayor bienestar por parte de toda la población, facilitó la marcha sin grandes obstáculos y dificultades del proceso democrático $\rightarrow$ no obstante los defectos institucionales reconocidos-, en la medida en que la mayoría ciudadana avanzaba sin titubeos sus nuevas aspiraciones con una firme creencia en su efectiva posibilidad. Los conflictos de intereses podían regularse con relativo éxito y su mayor satisfacción - contenida aquí o alla por el momento- sólo era cuestión de tiempo dentro de una acción politica sostenida. ¿Qué sucedería si la expansión que había mantenido una mayor moderación en las luchas tradicio- 
nales comenzaba a dar señales de estancamiento?

$\mathrm{La}$ ecuación riqueza $=$ pluralismo mantenida con insistencia por algunos politólogos desde hace treinta años, se traduce ahora en el paralelismo, afirmado con igual convicción por otros, entre desarrollo económico y democracia. Dada la hipótesis, los impedimentos a la democracia en los países occidentales (incluido Japón) en el pasado inmediato y en la prospectiva de los ańos venideros constituirían a su vez un factor decisivo en las experiencias limitadoras del desarrollo económico, que por otras causas amenazan en el futuro. Como es natural, la tesis interesa sobremanera a los paises no desarrollados dentro de un capitalismo dependiente; pudiera ser que incluso su inicial planteamiento, implícito todavia, tuvo que hacerse en referencia a esos países, en el contenido doctrinal de las admoniciones 'modernizantes' que se les dirigfan.

¿Hasta qué punto se trata de una tesis irrefutable a pesar de las experiencias que parecen por el momento confirmatorias? Porque la tesis no sólo destaca las dificultades del régimen democrático para la coordinación o dirección general de la economía, sino que subraya además los efectos desmoralizadores en la conciencia politica tanto de la inflación como de la recesión --con peso distinto en los diferentes sectores sociales-, y más aún no sólo en el caso a veces de su presencia conjunta sino, sobre todo, en el de su incomprensible alternancia en ocasiones. El examen de la correlación entre desarrollo económico y democracia obligaría a perseguir un número nada pequefio de presuntas relaciones causales internas sin cuya consistencia comprobada queda aquella correlación -10 mismo que cualquier otra- como mera apariencia o fachada. En este examen rapidísimo del tema principal parece obligado sortear semejante intento, dado el tiempo que habría de absorber. Aceptemos de manera provisional que la correlación manifiesta cierta validez transitoria relativa al momento histórico en que ha sido captada. Pero en este caso aún quedan dos grandes cuestiones que no pueden ser eludidas. La primera consiste en el hecho de que las ideas liberales y democráticas son anteriores e independientes en la historia del pensamiento de las concepciones sobre el desarrollo económico. Ante la döctrina que luego recogeremos, de que la legitimidad del régimen democrático no es otra que la del éxito y eficacia del sistema económico, conviene recordar enérgicamente que el tipo de dominación que caracteriza al Estado moderno y que de alguna manera sostiene tanto sus elementos liberales (derechos políticos) como sus democráticos (la 'representación' como competencia legal) tienen su origen en el despliegue de las concepciones jusnaturalistas antes y después de la modernidad. Recuérdese el capítulo sobre el derecho natural en la sociología jurídica weberiana (en modo alguno un tratado filosófico) en donde se pone de manifiesto que los supuestos de la dominación legal pasan por el momento de fe de la aceptación de una inspiración carismática. Por tanto lo mismo el Estado constitucional moderno, como su posterior estructura democrática, se desenvuelven y toman cuerpo histórico sin relación esencial con las concepciones concretas del sistema capitalista y por consiguiente que lo mismo el Estado de Derecho como la concreción institucional de las aspiraciones igualitarias de la democracia, no han sido formulados ni definidos en función de lo que ahora llamamos desarrollo económico. Las garantías de los derechos individuales públicos y privados anteceden 
históricamente a las preocupaciones por el crecimiento del sistema económico. $Y$ si bien es verdad que la racionalidad jurídica del Estado tiene su paralelo en la racionalidad burocrática de todo tipo de empresa, no es menos cierto que el desarrollo de la burocracia moderna fue en principio indiferente a la extensión de la democracia, aunque de hecho la favoreciera dentro de ciertos límites. La puesta en marcha de la dominación legal -del Estado moderno de derecho- y de los proceso democráticos - por la sucesiva ampliación del derecho de sufragionunca se propusieron de manera directa fomentar el desarrollo económico. Pudieron por eso darse en paises de crecimiento lento, como apenas existir o sólo de manera deficiente en otros paises de un crecimiento económico acelerado. La historia europea es a este respecto ejemplar, pues la pobreza no impidió no sólo la aspiración apasionada por la democracia sino el mejoramiento paulatino de su implantación. La historia de los distintos partidos, de sus doctrinas, y de una sostenida formación de hábitos y tradiciones políticas, tiene en alguno de esos países su centro de inspiración. No se compare la situación con los Estados Unidos, donde condiciones enteramente diferentes permitieron la afirmación temprana del elemento riqueza.

Al peso y continuidad distintas $y$ peculiares de tales usos y tradiciones se debieron, como se dijo, las diferencias en la capacidad de sortear con mayor o menor éxito las dificultades enfrentadas por las democracias en los últimos tiempos, algunas de las cuales se mantuvieron con ejemplar vigor durante los recientes años de recesión económica. $Y$ cualquiera que sea el entrelazamiento o independencia entre las instituciones políticas y las económicas - lo que no vamos a examinar aqui-, no hay duda alguna que esas arraigadas vigencias de la educación polftica serán decisivas en la conformación cultural de la recuperación económica previsible todavía para los próximos años - con altibajos seguramente- así como en la orientación que habrán de seguir los países más importantes en la denominada busca de su 'identidad', tal como se espera en las décadas inmediatas luego de las vacilaciones vividas en los primeros conatos de la pretendida détente. Si las democracias logran rehacer sus fisonomías tradicionales en el futuro inmediato, en ese reajuste de su 'personalidad' es muy posible que se muestren también capaces de reafirmar su 'voluntad' de continuidad política aun en el caso de llegar el momento - problemático en cuanto a fechas y naturaleza de sus factores detonantes-, en que se vean obliga das a aceptar limitaciones de distinto gra do en su desarrollo económico, sin por eso entrar en un definido estado estacionario. Aunque algunos sostienen que la estructura económica del capitalismo presenta menores capacidades de adaptación que la socialista a los problemas de esa condición, no puede adelantarse a priori como seguro que los mecanismos políticos democráticos de compromiso, transigencia y acomodo de los respectivos sacrificios sean necesariamente inferiores a las rigideces que a la larga lleva consigo la imposición burocrática autoritaria.

iv) Estrechez de los limites nacionales

El último de los factores en la crisis de la democracia contemporánea que suelen señalar con singular consenso sus diversos estudiosos, es el derivado del hecho de haberse contraído o estrechado cada vez más el ámbito de los límites nacionales frente a la amplitud e interdependencia de la economía mundial. Entraba en la definición misma del Estado su carácter 'territonial'; la capacidad de 
su mando y la extensión de su esfera juridica sólo cubrian un territorio delimitado celosamente por sus fronteras. Pero a su vez toda actividad llevada a cabo dentro de ese espacio por ciudadanos de otros países quedaba sometida a sus propias normas, las cuales tanto podran permitirla como limitarla o sancionarla negativamente. $Y$ aunque esta situación era válida para cualquier clase de Estado, los de carácter democrático tenían que contar en alguna medida con un minimo de conocimiento y participación de su opinión pública, tanto en esos casos como en los de su acción exterior o internacional, no sin cierta cautela desde luego. Pero las dimensiones de una economía notoriamente cada dia de mayor tendencia global, rompieron virtualmente con la efectividad de las fronteras teóricamente intactas, la auténtica capacidad del Estado nación, lo mismo para ampararse exclusivamente tras ella en su pretensión soberana como para impedir de hecho la repercusión en su interior de actividades, movimientos y presiones externas ante su impotencia para controlarlas desde su centro de poder. La experiencia de los últimos años muestra que ni siquiera los Estados democráticos más poderosos económicamente pudieron escapar a los impactos de su mundo entomo. El fenomeno de las transnacionales parecería imponerse como el ejemplo de primer plano más observable, aunque esté muy lejos de ser en verdad lo más importante y profundo. La historia económica reciente conoce de sobra las ondas sucesivas de presiones y contrapresiones que se dieron como resultado de polfticas económicas nacionales, fuera por lo demás sin duda alguna de sus originarios propósitos. La recuperación económica de Europa y del Japón promovida por los Estados Unidos creó en los años subsiguientes serias dificultades en las relaciones económicas recíprocas entre las partes interesadas. Tal como se ofreció más tarde la repercusión de las inflaciones 'exportadas' o los efectos financieros de las políticas conjuntas de los países petroleros y las de explicable defensa de las naciones clientes. El espacio territorial del Estado se contrae y las democracias perciben en ese encogimiento que carecen de los mecanismos para intervenir 'democráticamente' frente a los nuevos y más amplios espacios en donde no pueden menos de actuar. Unicamente sobre ese trasfondo general cabe hacer inteligible el problema de las citadas 'transnacionales', que lejos de crear, como algunos han sostenido, un nuevo tipo de sociedad internacional en que tienda a desaparecer u opacarse el viejo Estado soberano, le plantean por el contrario a ese Estado, al que continúan aún sometidas como su suprema autoridad, no pocos problemas de control tanto político como económico. Las cuestiones que origina la creación de un nuevo orden económico internacional imponen, con mayor o menor urgencia, el establecimiento de 'autoridades' internacionales en donde necesitan participar los gobiernos democráticos sin que la naturaleza a su vez democrática de las mismas esté definida y pueda asentarse claramente y con eficacia.

La exígencia de polfticas regionales - con la constitución de unidades de tal carácter, económicas y políticas en su término- pone claramente de relieve la dificultad de superar las angosturas de los ámbitos nacionales y la impreparación de los regímenes democráticos para trasladar a las proyectadas unidades, los procedimientos usuales de sus propios sistemas. La novedad de las situaciones creadas por la interdependencia económica sorprende al pensamiento $y$ a la acción política con urgencias de imagina- 
ción que no se presentan de igual suerte ante los demás factores de crisis conocidos y estudiados por más tiempo. Las tareas de reconstrucción o restauración se convierten en este caso en actos de auténtica invención.

\section{b) Interpretación liberal}

La arraigada proclividad mental a la clasificación nos hizo adelantar una interpretación calificada de liberal al lado de la más funcionalista y conservadora que acaba de examinarse. En su estricto significado más que una interpretación diferente equivale a un matiz de la anterior, que no deja de manifestarse agudamente por cierto en la redacción del informe citado. Por una parte, destaca en su dirección crítica la veta peculiarmente liberal, que en la tradición europea suele separarse netamente de la participatoria democrática e igualitaria; la influencia por ejemplo de Stuart Mill con su doctrina de la naturaleza esencialmente representativa del régimen democrático o la de un Tocqueville con sus temores ante la posibilidad de que pudiera darse algún dfa con el avance de la democracia la aserción antiliberal de una 'mayoría' impulsivamente autoritaria. Por otra parte los supuestos sociológicos de este sector de pensadores liberales la separan de una mera concepción funcionalista - siempre orientada por el predominio del orden y la armonfa social-, para subrayar en cambio no sólo la inevitabilidad de la lucha y del conflicto sino el valor positivo incluso de su existencia. Toda concepción democrática-liberal del sistema político tiende a aceptar en consecuencia como su punto de partida la existencia de contraposiciones de intereses y de posturas ideológicas, que irreducibles al imperio de una solución definitiva al dictado de una verdad absoluta poseída en cuanto tal, sólo pueden alcanzar arreglos transitorios, históricamente suficientes en su sucesiva ampliación, logrados por medio del acuerdo, el compromiso y la atenuación mutua de los extremos incompatibles. De ahí el valor democrático de los procedimientos que permitiendo esa concordancia y cesión recíproca representan la institucionalización del conflicto; es decir, el valor de la condición liberal consistente en respetar mientras dura la validez de los intereses y opiniones del contrario. Todo régimen que se crea en la posesión de una única verdad y no tolere la que parezca disonante, impidiendo con su discusión un posible acuerdo relativamente satisfactorio, es en principio autoritario sin atenuaciones aunque se entregue en la expresión voluntariosa de una mayoría democráticamente elegida. Ante las dificultades y peligros de las democracias contemporáneas, los pensadores inspirados todavía por esa veta de la tradición liberal señalan más que nada to que en ella se encuentra amenazado por exceso o por defecto. La breve intervención de R. Dahrendorf en la discusión de los informes de la mencionada "Comisión Trilateral' manifiesta con veracidad la postura que en unión de otros, desde luego, había ya defendido en más de una ocasión. Juzga inadmisible por consiguiente la aceptación de cualquiera propuesta de 'saneamiento' que implique de hecho recortes o limitaciones del proceso democrático, aunque aparezca apoyada por una teoría sobre la existencia de elementos disfuncionales en el sistema. Unas breves refèrencias no sobran a este respecto. La preocupación por la supuesta hermandad entre democracia y desarrollo sólo serfa admisible de aceptarse una posible concepción de este último mucho más amplia y humana. liberada del exclusivo imperio que todavía ejerce 
el indicador fascinante del ingreso bruto. ¿Es que no caben formas distintas del desarrollo al servicio de la dignidad y libertad humanas? El recorte en la expansion educativa porque resulta adversa - en la superior singularmente- a los fines del desarrollo y de la estabilidad social, es un paso 'regresivo' para todo aquel que conciba a la educación ante todo como un 'derecho humano' al enriquecimiento de la personalidad. Las tensiones entre los medios masivos de comunicación y los poderes de gobierno no pueden encontrar su solución en la asfixia - limitación de sus efectos culturales. Y hay que tener el coraje de señalar por último las amenazas que trae consigo toda amplitud desmesurada de la aspiración 'participatoria' alli donde su introducción conduzca de hecho a la inmovilización del proceso político. Lo que más importa salvar en la democracia de hoy es el sentido tradicional de la 'ciudadanía', incluso frente a los peligros de intentos muchas veces generosos de perfeccionarla. La tradición liberal ha de conocer y aceptar sus propios limites, pues caso de no hacerlo entraria en trance de estrellarse. Estas resonancias de los grandes clásicos del liberalismo politico, adelantan las notas de un pensamiento 'restaurador' que quizá tome fuerza por muchas partes sin necesidad de romper su profunda relación dialéctica con las esperanzas revolucionarias más agresivas de los ideales de la nueva izquierda, o mejor de la parte más seria del pensamiento crítico contemporáneo.

\section{c) Interpretación de la mieva izquierda}

Pero si ahora tomamos la mano de la nueva izquierda su visión de la crisis de la democracia contemporánea nos saca por completo del terreno por el que andába mos. Pues ya no se trata de aislar los factores negativos de desintegración para enmendar en lo posible los malos hábitos, sino de mostrar que padece de una dolencia fatal; lo que impone contemplar en todo caso su futuro sobre bases radicalmente distintas. Pues el diagnóstico de este tipo de pensamiento percibe ese mal esencial como un derrumbe completo de los principios de su legitimidad. Y como se parte ahora otra vez de una correlación constitutiva entre democracia y desarrollo, la crítica se extiende asimismo a cualquier otro sistema político que haya unido su suerte a la eficacia de tai desarrollo. Pero atengámonos por lo pronto a los países occidentales, donde democracia y capitalismo entrelazan en único sistema las dos vertientes economica y política. Cierto es que junto a la nueva izquierda, entregada vigorosamente a una crítica cultural de gran amplitud, otras corrientes menos heterodoxas habian cuestionado a su hora el problema de la legitimidad de distinta manera; es decir, negándolo en cuanto tal. Pues a tenor de los teóricos de las formas políticas democráticas propias del capitalismo tardío o de mayor madurez, la totalidad del sistema preocupado únicamente por su propia estabilidad utiliza un complejo insttucional chya sola meta es la lealtad de las masas, es decir, poder lograr mera mente cierto estado de obediencia apática funcionalmente satisfactoria. De esta suerte el concepto tradicional se transforma en cosa distinta, pues no tanto importa fomentar la creencia en la validez de un orden político determinado como de estimular la renuncia a toda pretensión legitimadora (C. Offe).

La nueva izquierda no pretende esa renuncia ni reniega del víejo concepto de legitimidad, sino que plantea la falsedad quebradiza de los principios a que recurrió en un momento dado la parte más inteligente de la burguesía. Incapaz de 
secularizar de modo duradero las imágenes de legitimidad del poder formuladas por la Ilustración -sobre las ideas abstractas y casi sacras en sus orígenes de la libertad y la igualdad-, resolvió trasladar la legitimación de tal "clase política' a sus fundamentos económicos. He aquí como H.P. Dreitzel resume agilmente el proceso: "con el desarrollo del capitalismo monopolista y del intervencionismo estatal, la legitimidad de la burguesía dirigente y de la persistente desigualdad tuvo su base en el aumento constante del ingreso per cápita." Ya se vio antes la insinuación de esta idea en la critica conservadora, que no obstante emparentar democracia y desarrollo no implicaba con eso ningún principio de legitimidad. Sólo se pretendia una interpretación emprica del florecimiento de la organización democrática en los momentos de auge de! crecimiento económico, lo que permitra además justificar ciertos temores para e] caso de una atenuación o paro completo de ese crecimiento.

La nueva izquierda, sostenida por una crítica cultural generalizada de nuestra época, lleva a su extremo la negación de las bases dominantes de la legitimidad política, sin esperar a que unas u otras experiencias históricas concretas la derrumben por completo y deje de creerse efectivamente en ella. La misión de toda cultura en un momento dado consiste en proporcionar los fundamentos de legitimidad del sistema político, esclarecer además los supuestos de la estructura de las motivaciones personales e interpretar por último en forma simbólica las limitaciones naturales de la vida humana. Dicho en términos weberianos a este respecto: of recer algunos de los 'sentidos' fundamentales de la existencia del hombre. El antes mencionado H.P. Dreitzel, en un condensado y excelente resumen de la crítica cultural de nuestro tiempo, tanto de los movimientos espontáneos de las distintas 'contraculturas' como del análisis filosófico de pensadores importantes, trata de todos y cada uno de los puntos indicados, que en modo alguno vamos a repetir o glosar ahora. Nos basta con tener en cuenta, como en otros aspectos del pensamiento de la nueva izquierda, que el análisis de la democracia actual, a pesar del vigor y la generosa impetuosidad de su ataque, se estrella también en el momento de articular las necesarias propuestas de reconstrucción. ¿Qué es to que puede sustituir a la democracia industrial -capitalista o socialista- y en qué forma de vida económica sustentaria?

Sabido es que la crítica filosófica en su más rigurosa depuración conceptual ha insistido y quizá demostrado el desvarío que supone para la civilización el predominio de la razón instrumental. La razón práctica o quizá histórica, de las que dependen los valores a que los hombres aspiran en su vida cotidiana -valores éticos y estéticos, de sostén comunitario y de fraternidad-, han sido cada vez más opacadas por la instrumentalidad de la relación de fines y medios en la ciencia y la técnica, en el desarrollo económico y en la asesoría tecnocrática de las decisiones políticas, dejando al hombre concreto dolorosamente insatisfecho en sus aspiraciones más íntimas y vitalmente más indispensables. Toda la 'malaise' personal -psicológica- de nuestros dfas proviene de la alternancia entre la enajenación impuesta por las instituciones sujetas a la razón instrumental y la anomia derivada de la frustración de los valores personales (Dreitzel, Habermas, Schroyer, etc.). Las numerosas y confusas actitudes protestatarias de nuestra época - flor de un día en algunas de sus manifestaciones-, son la expresión inmediata en los hombres de carne y 
hueso de las tensiones señaladas. Sin embargo, todo este enérgico movimiento de rebeldía no ha podido dar aún en los sectores decisivos de los sistemas econó micos y políticos con las imprescindibles equivalencias funcionales.

Ante los peligros de trizaduras de las democracias de hoy las posiciones "conservadoras' y 'liberales' tratan de evitar el desastre que significa arrojar por la borda los valores y el sentido que todavía preservan, las 'viejas' instituciones, aun en su comprobación histórica deficiente.

La exaltación de la nueva izquierda, patéticamente humana, quizá no clame en vano en el desierto. Es posible que cada vez tome más fuerza en el futuro un tipo de pensamiento 'restaurador', dispuesto a integrar las justas críticas de los iconoclastas en el reforzamiento de todos los elementos valiosos de una civilización incapaz de mudar en un solo día, por arte de magia o por un acto de conversión religiosa, sus imperfectas instituciones, trabajosamente elaboradas al correr de un largo tiempo. Una necesaria tra bazón dialéctica pacientemente sostenida del pensamiento 'restaurador' y del pensar crítico quizá pueda ofrecer en su dia el equilibrio indispensable para dar con una posición constructiva. Se trata de la posibilidad de una nueva forma de inteligencia-manifiesta ya por algunas partesbien armada para enfrentar desde ahora el incierto futuro. Pero esto nos llevaría a una digresión que precisa parar en seco en estos instantes.

d) Las implicaciones de la sociedad postindustrial

Ya no tiene ese carácter, aunque pueda parecerlo dadas las dimensiones temporales que delimitan la prospección en estas páginas, una referencia necesa- riamente breve, a la imagen futura de la sociedad denominada 'postindustrial'. Porque en caso de realizarse de manera más o menos aproximada, entraría en nuestro tema cediendo a una interrogación acerca del tipo de gobierno que habría de corresponderle. ¿Tendría sentido hablar de la perduración en ella de la organización democrática?

Todos los que en estos dias conceden alguna atención a semejante estructura - comenzando incluso por su más detonido diseñador- acogen su presunta configuración con no pocas dudas. ¿Qué es lo que más a fondo involucra: un nuevo tipo de sociedad o una transformación del sistema capitalista? Postcapitalismo en suma ¿o sociedad postindustrial? Sin embargo, a pesar de esas dudas no niegan rotundamente la presencia de ciertos rasgos que pudieran definirla mañana como tal.

De esta suerte lo que fue hace años la anticipación imaginativa y utópica de un escritor inglés, tiene hoy que tomarse medianamente en serio. La idea de una Meritocracia, de una sociedad de rígida estructura piramidal, prefijada en sus diferencias de status por la adición de las diferencias en el cociente intelectual a los resultados de técnicas educativas sólo a cada uno de ellos asequible, comenzaria a mostrarse como el horizonte probable de una civilización dominada cada vez más por el saber cientifico. La ciencia y la técnica constituirían por eso la fuerza dinámica de ese futuro.

Antes de su pleno logro, las primeras manifestaciones de esa transformación, supuesta en sus inicios, pueden descifrarse en los desplazamientos que, con más o menos amplitud, transcurren en la estructura ocupacional, cuyo norte se sitúa en el predominio cualitativo del sector de servicios. Conjunta o previamente más bien el aumento en la demanda de la 
preparación requerida trajo consigo la contracción en ciertos límites de la mano de obra no calificada. A partir de esta constatación de evidencia estadistica en la mayoría de los países industriales, comienza la elaboración sociológica de los datos y el avance del pensamiento especulativo. Atenidos por ejemplo a la cuestión del desarrollo, ¿habrá éste de depender más de factores cualitativos que cuantitativos? ¿No se atenuarán sólo por eso los problemas que sus posibles límites presentan? Sin embargo, de acuerdo con nuestro tema, el aspecto político es el que ahora más nos interesa. Si el fundamento esencial de éstos y otros cambios se encuentra en la penetración cada día más intensa de la vida por la ciencia (Shelsky), sus manifestaciones polí ticas y económicas no podrán quedar exentas de su dominio. La creciente asesoria científica de las orientaciones politicas tho acabará por entregar a determinados expertos la responsabilidad exclusiva y plena en toda toma de decisiones? La política comienza a ser para algunos una mera ilusión.

Cuando D. Bell trata de enfrentarse con el tema se encuentra con la alternativa en los futuros centros de poder de tener que elegir entre los tecnócratas y los políticos; y aunque declara en definitiva su opción a favor de los últimos, no puede olvidarse que en su cuadro relativo a la estratificación del poder tiene sus notas decisivas en el predominio del conocimento, en la investigación universitaria, en la habilidad técnica, la educación, la cooptación, etc. A este respecto en la existencia de la cooptación como medio de acceso parecerfa darse lo decisivo. Pues no obstante la desvalorización de la tecnocracia como cúpula del poder político, no es fácil imaginar la democracia en un régimen político donde la cooptación sustituya a la votación fuera de excepcionales ćrculos. ¿Cómo sería el futuro ya próximo o más lejano de una democracia condicionada de esa ma nera? ¿Se trata de una tendencia con la que en todo caso hay que contar?

El propio Bell más liberal al parecer que demócrata (no se olvide una de sus preocupaciones: "El enigma sociológicamente fascinante en una sociedad democrática radica en el hecho de que a medida que disminuye la desigualdad crece al contrario el resentimiento", tiende a encontrar la fórmula en lo que sería una meritocracia verdaderamente justa.) Desde el punto de vista de la participación, de la presencia de los ciudadanos en el rumbo de las orientaciones políticas y de sus decisiones concretas, el enigma se plantearía de modo distinto, aunque tuviera que partir de la presencia de ese resentimiento. ¿Cómo tratar los resentimientos que se expresan más o menos explosivamente en las protestas contemporáneas? ¿No se trataría de averiguar sus diferentes causas - más acá de la condición humana- y Ia forma de hacerlos inofensivos o tolerables por su canalización adecuada? Volvemos así al tema de las dificultades de la democracia no sólo hoy sino mañana. Contentémonos con lo que ya ha sido rozado. 


\section{III \\ Recuperación de la efectividad democrática}

La sucinta exploración antes cumplida de la crisis en las democracias occidenta les -factores comunes y peripecias diversas- se emprendió preferentemente al amparo de intelectuales de inclinación derechista por tratarse de hombres más interesados en su subsistencia que en su acabamiento y término. Por lo tanto, los factores señalados por ellos como origen de sus debilidades permiten mantener la expectativa de una buena recuperación. Pero sería enojoso reiterar el camino antes recorrido en el inmediato examen de las proposiciones de mejora (zonas en las que se debe actuar y fijación de una 'agenda' de aceptación común). Todos los elementos negativos causados por desajustes de tipo institucional, con una historia nada breve en sus manifestaciones, son susceptibles de reformas orientadas por la inteligencia instrumental, con pleno valor en este campo; es decir, por la creación de nuevas técnicas de organización social, que no pretendan sin embargo ofrecerse como soluciones definitivas. En el caso de las medidas requeridas por la situación descrita metafóricamente como de contracción territorial, en la que todas se encuentran a la par, se exigen audaces esfuerzos de capacidad inventiva $y$ de originalidad creadora, aunque en su hallazgo pueda favorecerlas su enlace con las que se vayan instaurando en la busca común de un nuevo orden internacional. La prospectiva no se muestra totalmente adversa mientras dure sin grave deterioro la fase competitiva de la détente, en la que continuarán envueltas por bastantes años. Pues dentro de esa fase no es imposible poder implantar algunas ordenaciones parciales, aunque no se alcance con la rapidez deseable el nuevo orden total a que la mayoría de los parses manifiesta aspirar.

Por otra parte. se ha reconocido como supuesto de estas páginas la expectativa de que durante más de veinte años pueda darse un crecimiento económico no inferior al de las décadas previas a la actual recesión, no obstante preverse por los más pesimistas la ocurrencia de agravadas complicaciones técnicas dentro del sistema. Asumiendo sin embargo el caso más favorable constituirla sin embargo un grave error polftico persistir en la creencia de una correlación demasiado estrecha entre desarrollo económico y régimen democrático, al punto de hacer depender a éste enteramente de aquél. Al contrario, revitalizar el sistema democrático podría constituir un excelente instrumento para sostener la continuidad del desarrollo, en el caso en particular de que el aumento insoslayable al parecer de la planeación pudiera lograrse mediante la tarea, apenas emprendida hasta ahora con éxito, de utilizar el funcionamiento del régimen representativo como el mecanismo adecuado de una canalización paralela de las opciones económicas y políticas. O sea, el ensayo de un régimen político parlamentario que fuera al mismo tiempo el órgano eficaz de una planeación económica democrática, a base de la participación de todos los interesados, contando claro está de antemano con sus diferencias y antagonismos. Por otro lado, nada impide en el 
lapso de tiempo aún disponible que se intente un nuevo tipo de desarrollo menos obsesionado por sus indices cuantitativos y más interesado al contrario por los cualitativos. Lo que en tal caso pudiera conseguirse con una nueva relación entre desarrollo y democracia sería sin duda decisivo para la plasmación de formas distintas de vida, tal vez inéditas, capaces quizá de perdurar cuando los vientos de bonanza pasen y sea preciso enfrentar, como algunos temen, en tiempos más lejanos, la posibilidad de una condición económica estacionaria. Para esa época comvendría conservar a salvo lo más posible la flexibilidad y las capacidades de adaptación y cambio que guardan por principio las instituciones democra ticas.

El problema de la 'sobrecarga' de pretensiones en que parecen asfixiarse los gobiernos democráticos es a no dudarlo de naturaleza distinta, porque ya no depende por entero del éxito de la relación de medios y fines de una razón puramente instrumental. Constituye la misión insustituible de una educación política perseguida al resguardo de las razones práctica e histórica, únicas capaces de suscitar una conversión de las actitudes, hoy deterioradas o francamente pervertidas, de los individuos y otras unidades sociales frente al Estado. El problema, en efecto, de un liberalismo restaurado en medio de condiciones sociales y técnicas por completo distintas de las tradicionales. Un tema, que se ofrece estrechamente conexo con el de las bases esenciales de la plena recuperación de la vida democrática, es decir, el de la posibilidad de un retorno a fondo hacia sus auténticos principios de legitimidad. La impugnación de la nueva izquierda - de la reflexión sociológica en cuanto conciencia critica de nuestro tiempo- mantendrá todo su vigor, de persistir consin- tiéndose en la transposición de las razones de esa legitimidad, al aceptar sin vacilaciones su coincidencia o confusión con la eficacia técnica y el éxito en la gestión económica. La legitimidad del Estado de derecho, de su función liberal $y$ de la organización de la democracia como participación ciudadana responden a exigencias superiores enlazadas con el sentido de la vida en sí misma y en sus más humildes cristalizaciones. No hablemos de la felicidad por lo que tiene de inasible, pero sí largamente de los modos de evitar de manera consciente la ocurrencia de numerosos sufrimientos superables.

Fue un error de momentos positivistas el que hombres como J. Schumpeter y $M$. Weber (nunca puramente tales) se esforzaran por defender a la democracia, presentándola como un mero instrumento técnico para la elección de dirigentes. Hasta el ex tremo de llegar el áltimo, inti mamente liberal, a concebir su famosa fórmula de la demacracia plebiscitaria. Pero no es cosa de entrar en mayores explicaciones históricas.

Ni el Estado de Derecho ni la democracia pueden reducirse a su pura instrumentalidad. Y si quizá nuestra época no permite un retorno a la pristina justificación jusnaturalista de uno y otra (fundamentos religiosos secularizados), al menos parecería necesario aprovechar lo que todavía persiste vivo de esas creencias con los distintos sentires nacionales (el núcleo de los valores políticos a los que se refiere para Francia el funcionalista M. Crozier: libertad e igualdad) y poner en marcha una renovación de la 'voluntad' política abierta a la protesta dolorida de innecesarias frustraciones, es decir, que 'quiera' situar de nuevo los fundamentos de la legitimidad democrática, más allá del racionalismo instrumental, en los valores supremos de una conviven- 
cia humana con auténtico sentido para el hombre y su comunidad. El futuro de la democracia occidental dependerá de que sea capaz de reencontrarse otra vez a sí misma - su 'identidad' renovada - en el conato generoso y entusiasta de la histórica constelación de sus orígenes.

En un manual de Sociología Política de bastante difusión en los medios escolares (Roger-Gerard Schwartzenberg), en su no muy lejana edición (1971) ahora a nuestra vista, contenfa a manera de confrontación significativa dos capítulos titulados "sous-développement et surpouvoir" y "sur-développement et souspouvoir". Se desplegaba en ellos una doctrina, válida entonces al parecer, en la que se sostenf́a la existencia de una correlación entre el grado de desarrollo económico y el grado de efectividad del poder político. Los países en trance de desarrollo parecían necesitar para su pleno logro de gobiernos çon procedimientos enérgi$\cos$ y de amplia aptitud movilizadora, mientras que los países democráticos de poderoso desarrollo económico manifestaban por el contrario una singular atonía en sus poderes públicos. Sucedía por añadidura que al tiempo de esa debilidad en los órganos del régimen representativo irrumpia la presencia de una fuerte reacción de la sociedad frente a un crecimiento económico obsesivo, en contra de la superabundancia de riqueza (ocurría cabalmente en los Estados Unidos, en la década de la más intensa eclosión de las liamadas 'contraculturas'). No puede declararse sin más que todo sea ya historia pasada. Pero no cabe sostener, al cabo de los pocos años transcurridos, que pueda valer todavía la correlación inversa antes formulada, con su innegable impacto impresionante. En el apretado correr de estas páginas se ha mostrado patente, por el contrario, en las democracias más ricas una invocación angustiada de una mayor autoridad as como una intensificación del intervencionismo estatal, destinado a crecer al ritmo impuesto por la extensión, en una $u$ otra forma, de la planeación económica. Lo que para entonces preocupa a los observadores citados y otros más, es que pueda darse tal condición sin perturbaciones fatales en el seno del régimen democrático establecido. Es lo más posible que no sea así, pero sólo en el caso que ese régimen esté dispuesto a restablecer su enérgica historia y sea capaz de hacerlo.

Pero isigue en pie la alternativa opuesta de la correlación? ¿A los países en desarrollo no les queda otra vía que la puramente autoritaria, sin apenas opción alguna a la representación ciudadana, a la participación popular?

Se hubo de partir de una constata ción de hecho respecto de los parses latinoamericanos; el hecho de que en su gran parte impere hoy una preferencia por regimenes autoritarios, que al menos han puesto en paréntesis temporal el ejercicio de los procedimientos liberaldemocráticos que antes conocían y practicaban. La mera declaración de ese 'paréntesis' indica la presencia de reservas y de que no se trata de una decisión tan indefinida como para parecer definitiva. Una vez más los países incluidos en tales circunstancias reiteran su contradicción originaria en la racionalidad respectiva de sus instituciones políticas y económicas. Nada nuevo por cierto en su historia y tantas veces seffalado además que elimina su consideración por el momento. Hoy se justifica la contradicción aducida como resultado inescapable de las tensiones y conflictos precipitados por la acción de su mismo crecimiento económico, que no pudieron resolverse en tiempo oportuno por medio de compromisos eficaces - aceptables por los interesados contendientes en espera de 
otros posteriores-, dentro del juego que permitían sus instituciones democráticas y liberales ya centenarias. Sin embargo lo que ellas significan en su arrastre histórico no se ha olvidado, ni nunca se ha negado a fondo.

Pero ahora no nos interesa ese tema por sí mismo, sino proseguir tan sólo las insinuaciones de prospectiva involucradas en las páginas anteriores. Los países latinoamericanos han incrementado en su conjunto su riqueza y bienestar sin lugar a duda durante los pasados años. De ser cierto que en el horizonte previsible de dos o tres décadas se ofrece con signo auspicioso la posibilidad de un crecimiento económico general continuado, no sería insensato anticipar para los países latinoamericanos un nuevo enriquecimiento, a la misma distancia o quizá menor que hasta ahora mantuvieron res pecto a los países centrales. Caso de confirmarse la prospectiva asimismo favorable de la continuidad democrática en los paises capitalistas, el modelo que de esta suerte se ofreciera podría quizá contribuir a limar las aristas autoritarias que prevalecen en la región. Si con esto se entiende naturalmente que no se trata de imaginar interferencias y presiones -en su mayoria de efectos negativos- ni tampoco de mimetismos mecánicos, impensables respecto de países en su plena mayoría de edad, sino de la presencia de un clima polftico generalizado que no podrán menos de respirar las naciones latinoamericanas, miembros por derecho propio de una común cultura y con per- manentes conexiones espontáneas -económicas, políticas, culturales y técnicocientíficas- con las grandes democracias todavía con un futuro abierto. Claro está dentro de las condiciones generales del orden económico mundial, mientras conserve aproximadamente ese carácter.

Los días azarosos en que vivimos no permiten confiar de pleno en el instrumento de la persuasión; las circunstancias colectivas son impulsorias y de su desarrollo conjunto depende la acción que en su caso pueda tomarse. Pero no debiera olvidarse que todavía perdura en la conciencia de los pafses occidentales la resonancia de las serenas palabras de Stuart Mill escritas al término de su ponderado ensayo sobre la libertad: "El va lor de un Estado, a la larga, es el valor de los individuos que lo componen. Un Estado que empequeñece a sus hombres hallará que con hombres pequeños ninguna cosa grande puede ser realizada". Una convicción del gran clásico del liberalismo, compartida con otros pensadores de su talla, que exalta el sentido supremo de la política y el valor decisivo de lo humano en la conformación de un orden social perdurable. Ese orden constituye la meta cabalmente de la preocupación futurológica, hasta el punto de situarla por encima de la prospección, en definitiva 'reaccionaria', de las posibilidades tecnológicas y de puro contento ma terial -ingresos y recursos- del hombre sobre la tierra. Una civilización está en efecto sin remedio amenazada si sólo prevalece en ella este último cuidado.

\section{Alusiones Bibliográficas}

Bell, Daniel, The Coming of Post-Industrial Society, Nueva York, 1973.

Bell, Daniel, The Cultural Contradictions of Capitalism, Nueva York, 1976. 
Bottomore, T.B., Sociology as Social Criticism, Londres, 1975.

Cardoso, F.H. y Faletto, E., América Latina: Proceso Interno y Orden Mundial, Santiago, 1976 (mimeografiado).

Crozier, Huntington, Watanuki, The Crisis of Democracy, Nueva York, 1975.

Dahrendorf, R., Gesellschaft and Demokratie in Deutschland, Munich, 1965.

Dahrendorf, R., Gesellschaft und Freiheit, Munich, 1961.

Faletto, E., Politica y Comportamiento Sociales en América Latina, Santiago, 1976 (mimeo).

Flechtheim, Ossip R., Futurologie. Der Kampf um die Zukunft. Fisher, Hamburgo, 1972.

Flechtheim, Ossip R., Zeitgeschichte und Zukunftspolitik, Hamburgo, 1974.

Habermas, Jurgen, Legitimation Crises, Boston, 1975.

Heilbroner, Robert, An Inquiry into the Human Prospect, Nueva York, 1975.

Heilbroner, Robert, Business Civilization in Decline, Nueva York, 1976.

Heimann, E., Teoria Social de los Sistemas Económicos, Madrid, 1968.

Graciarena, J., Transformaciones del poder y contradicciones del desarrollo latinoamericano (manuscrito; en publicación).

Medina Echavarría, J., Discurso sobre politica y planeación, México, 1972.

Moore, Barrington, Reflections on the Causes of Human Misery and Upon Certain Proposals to Eliminate Them, Boston, 1970.

Ogge, Claus, Politische Herrschaft und Klassenstrukturen, en Kress \& Senghaas, Politikwissenschaft, Francfort, 1969.

Schelsky, H., Auf der Suche nach der Wirklichklit, 1967.

Schroyer, Trent, The Critique of Domination. Nueva York, 1973.

Schumpeter, J., Capitalismo, Socialismo y Democracia, Madrid, 1971.

Stuart Mill, John, Sobre la Libertad, Madrid, 1970.

Schwartzenberg, Roger-Gerard, Sociologie Politique, París, 1971.

Touraine, Alain (ed.), Au-delà de la crise (Norman Birnbaum, Hans Peter Dreitzel, Serge Moscovici, Richard Sennet, Rudi Supek), Seuil, París, 1976.

Weber, Max, Economía y Sociedad, México, 1974. 